Research Article/Araştırma Makalesi

\title{
The Effect of Context-Based Learning Approach on Prospective Teachers' Understanding of Nanotechnology
}

\author{
Hülya DEMİRCIOĞLU *1 (D) Rabia ÖZDEMİR ${ }^{2}$ \\ ${ }^{1}$ Trabzon University, Fatih Faculty of Education, Trabzon Turkey, hulyadem76@hotmail.com \\ ${ }^{2}$ Trabzon University, Fatih Faculty of Education, Trabzon Turkey, r7zdmr@hotmail.com \\ * Corresponding Author: hulyadem76@hotmail.com
}

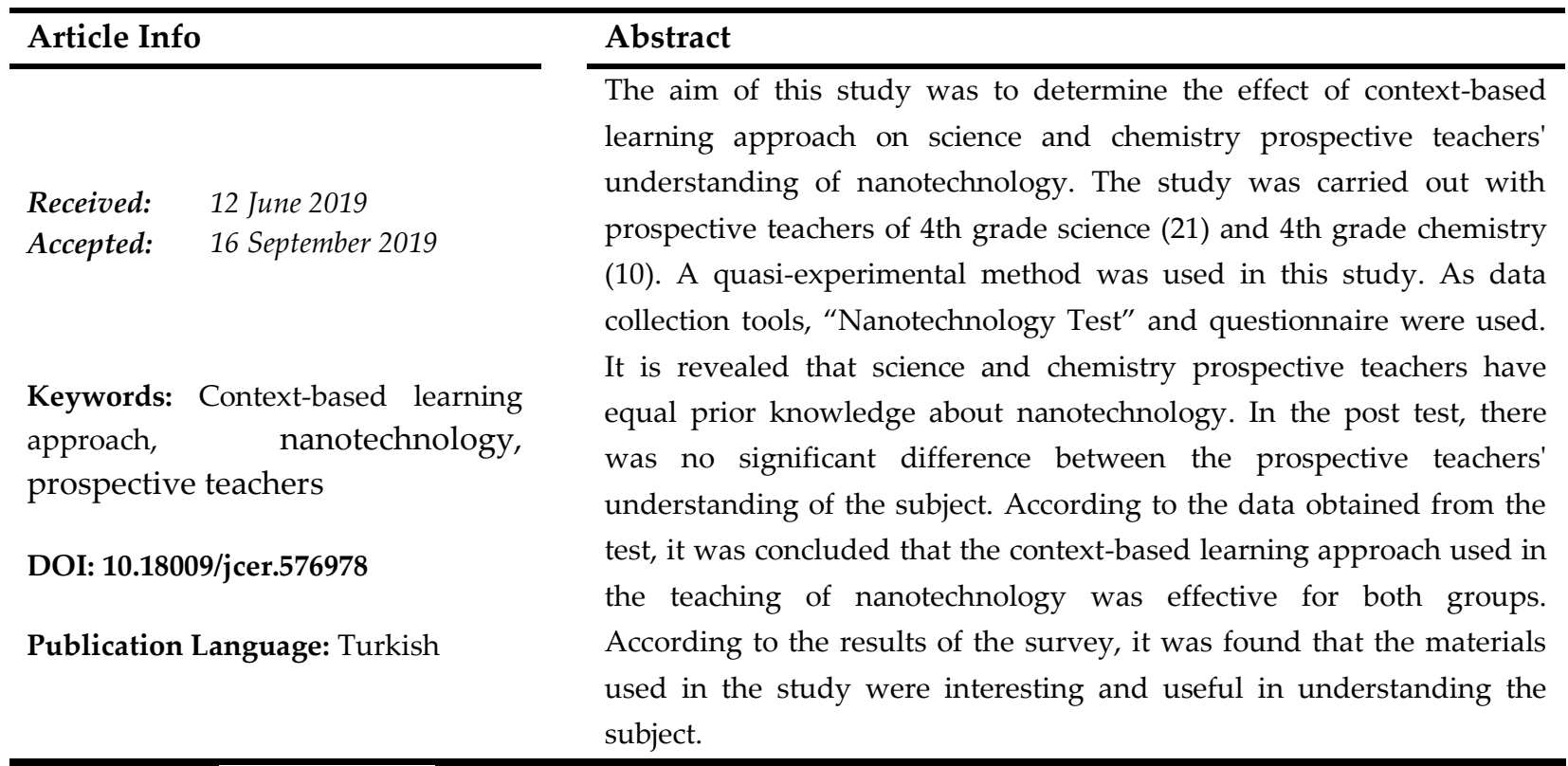

open $\bigcirc$ access CrossMark (c)

To cite this article: Demircioğlu, H. \& Özdemir, R. (2019). Bağlam temelli öğrenme yaklaşımının öğretmen adaylarının nanoteknoloji konusunu anlamaları üzerindeki etkisi. Journal of Computer and Education Research, 7 (14), 314-336. DOI: 10.18009/jcer.576978

\section{Bağlam Temelli Öğrenme Yaklaşımının Öğretmen Adaylarının Nanoteknoloji Konusunu Anlamaları Üzerindeki Etkisi}

\begin{tabular}{|c|c|}
\hline Makale Bilgisi & $\ddot{\mathrm{O} z}$ \\
\hline & $\mathrm{Bu}$ çalışmanın amacı, bağlam temelli öğrenme yaklaşımının fen bilgisi \\
\hline 12 Haziran 2019 & ve kimya öğretmen adaylarının nanoteknoloji konusunu anlamaları \\
\hline 16 Eylül 2019 & üzerindeki etkisini tespit etmektir. Çalışma, 4 . sınıf Fen Bilgisi (21) ve 4 . \\
\hline $\begin{array}{l}\text { Anahtar kelimeler: Bağlam, } \\
\text { bağlamsal öğrenme, gerçek yaşam } \\
\text { problemleri, problem çözme, } \\
\text { matematik eğitimi }\end{array}$ & $\begin{array}{l}\text { Sınıf Kimya (10) öğretmen adayları ile yürütülmüştür. Çalışmada, yarı } \\
\text { deneysel yöntem kullanılmıştır. Veri toplama aracı olarak } \\
\text { "Nanoteknoloji Testi” ve anket kullanılmıştır. Fen Bilgisi ve Kimya } \\
\text { öğretmen adaylarının nanoteknoloji konusu hakkında ön bilgilerinin } \\
\text { denk olduğu ortaya çıkmıştır. Son testte de öğretmen adaylarının konu } \\
\text { hakkında anlamaları arasında anlamlı fark olmadığı görülmüştür. }\end{array}$ \\
\hline DOI: $10.18009 /$ jcer.576978 & Testten elde edilen verilere göre, nanoteknoloji konusunun öğretiminde \\
\hline & kullanılan bağlam temelli öğrenme yaklaşımının her iki grup için de \\
\hline Yayım Dili: Türkçe & etkili olduğu sonucuna ulaşılmıştır. Anket sonuçlarına göre, çalışmada \\
\hline & kullanılan materyallerin ilgi çekici ve konunun anlaşılmasında faydalı \\
\hline & olduğu görüşleri ortaya çıkmıştır. \\
\hline
\end{tabular}




\section{Summary}

\section{The Effect of Context-Based Learning Approach on Prospective Teachers' Understanding of Nanotechnology}

\section{Introduction}

Developments in the field of nanotechnology, which is the key technology of our age, are gaining momentum day by day. The growing interest in nanotechnology has become the focus of interest in many disciplines. As a result of various disciplines, such as physic, chemistry, biology, computer, materials science, medicine, defense, industry, electronic, textile, being affected by nanotechnology, many studies have been put forward (Porter \& Youtie, 2009). There are many reasons why this technology can be found in every aspect of our lives. Considering the benefits of making more production with less cost, improving product quality, lowering energy costs and improving our quality of life, the necessity of this technology also arises (Ateş \& Üce, 2017). For this reason, it is a necessity for educators to have sufficient information equipment especially about nanotechnology awareness.

When the studies in the literature are examined, unfortunately, there are deficiencies in nanotechnology education in our country (Karataş \& Ülker, 2014). This issue is included only in the $12^{\text {th }}$ grade $4^{\text {th }}$ unit of the Secondary Education Chemistry Teaching Program as a single learning outcome (MEB, 2018). Context-based learning approach is a form of teaching in which students are responsible for their learning, especially in connection with daily life of difficult science subjects (Demircioğlu, 2008). The most important reason why context-based learning approach is preferred for teaching this subject is that the application areas of the subject are intertwined with daily life. Another important issue is to increase the level of knowledge by creating nanotechnology awareness among prospective teachers and to help them to direct their students to this field which is the technology of the future (Enil \& Köseoğlu, 2016). 
The aim of this study is to determine the effect of context-based learning approach on science and chemistry prospective teachers' understanding of nanotechnology. For this purpose, the following sub-problems are mentioned:

1) Does context-based learning approach have an impact on prospective teachers' understanding of nanotechnology?

2) Is there a difference between the level of understanding of nanotechnology in $4^{\text {th }}$ grade science and $4^{\text {th }}$ chemistry prospective teachers?

3) What are the prospective teachers' views on teaching based on context-based learning approach?

\section{Method}

A quasi-experimental method was used in this study. The study was carried out with prospective teachers of 4 th grade science (21) and 4th grade chemistry (10). As data collection tools, “Nanotechnology Test" and questionnaire were used.

In the application, the story, documentary and worksheets related to the definition of nanotechnology, related science branches, the purposes of use of nanotechnology, its relationship with daily life, its benefits, harms and its impact on society and environment were used. The materials prepared for each content of the subject are presented to the students considering the instructional design used by Watters (2004) in context-based approach.

\section{Discussion and Conclusions}

The difference between the pre-test means of chemistry and science prospective teachers was not statistically significant $(\mathrm{t}(29)=2,045 ; \mathrm{p}>0.05)$. From this it is understood that the groups' prior knowledge about the subject is equivalent. The difference between the means obtained from the post-test of chemistry and science prospective teachers was not statistically significant $(\mathrm{t}(29)=2,045 ; \mathrm{p}>0.05)$. However, as a result of dependent $\mathrm{t}$-test analysis, the difference between pre-test and post-test scores was found to be statistically significant in favor of post-test $(\mathrm{p}<0.05)$. This result shows that context-based learning approach used in the study is effective. Also in the literature, in many studies based on the context-based learning approach, there are findings that this approach helps to improve understanding in students (Yager \& Weld, 1999; Tsai, 2000; Holman \& Pilling, 2004; Demircioğlu, Demircioğlu \& Çalık, 2009; Ültay \& Çalık, 2012; 
Demircioğlu, Dinç \& Çalık, 2013; Demircioğlu, Ayas, Demircioğlu \& Özmen, 2015; Demircioğlu, Bektaş \& Demircioğlu, 2018; Demircioğlu, Aşık \& Yılmaz, 2019).

When the studies conducted on the context-based learning approach are examined, it is revealed that learning is more fun with the use of this approach especially in the teaching of subjects that are difficult to learn and abstract (Ramsden, 1997; Reid, 2000; Banister \& Ryan, 2001; Demircioğlu, 2008; Box \& Sözbilir, 2011; Topuz, Gencer, Bacanak \& Karamustafaoğlu, 2013; Karslı \& Yiğit, 2015; Yıldırım \& Gültekin, 2017; Demircioğlu, Bektaş \& Yılmaz, 2018; Demircioğlu, Aşık \& Yılmaz, 2019). The data obtained from the survey also support this opinion. In particular, the teaching of nanotechnology, which is difficult to understand and abstract, in connection with daily life has aroused interest in students and facilitated their understanding. 


\section{Giriş}

Bilim ve teknoloji alanındaki gelişmeler, Sanayi Devrimi'nden günümüze kadar önemli ilerleme ve değişmeler kaydetmiştir. Bunun sonucu olarak "bilgi toplumu" adı verilen, bilimsel okuryazarlığın gün geçtikçe daha da önem kazandığı bir topluluk ortaya çıkmıştır. Bilgi toplumu ile ön plana çıkan bilgi, üretim süreçlerini etkileyen önemli bir faktör haline gelmiştir (Aktan \& Vural, 2016). Bunun sonucu olarak insanlık için faydalı ve günlük hayatı kolaylaştıran birçok ürün geliştirilmiştir. Çağımızın anahtar teknolojisi konumunda olan nanoteknoloji alanındaki gelişmeler gün geçtikçe hız kazanmaktadır. Günümüzde fizik, kimya, biyoloji, bilgisayar, malzeme bilimi, elektronik gibi alanlarda kullanımının yanında, tıp alanında da oldukça çarpıcı gelişmelere imkân sağlamaya başlamıştır (URL-1). Buruşmayan gömlek, ıslanmayan mayolar, askerler için kir tutmayan çamaşırlar, kokmayan çoraplar, yüksek katlı binalardaki kir tutmayan camlar, yüzücüler için yunus balığı derisi ile aynı özelliğe sahip suyun içinde daha hızlı hareket etmeyi sağlayan mayolar, koşucuları rüzgâr gibi dış etkenlerden koruyarak sürtünmeyi azaltan giysiler bugün bilinen en önemli nano malzeme uygulamalarından bazılarıdır (URL-2). Teknolojide bir devrim niteliği taşıyan bu gelişmeler, insanlık tarihi açısından çok büyük bir öneme sahiptir (Tüylek, 2016). Bu yüzden nanoteknoloji, 21. yüzyılın en önemli alanlarından biri olarak karşımıza çıkmaktadır. Bu kavram ilk olarak ünlü fizikçi Richard Feynman'ın 1959 yılında katıldığı bir kongrede; atomları istediğimiz gibi düzenleyebilmemizin mümkün olabileceğini söylemesi üzerine ortaya çıkmış ve ilgi uyandırmıştır (Körözlü, 2016). Nanoteknolojik ürünler, metrenin milyarda biri kadar yani $10^{-9} \mathrm{~nm}$ boyutuna sahip küçük yapılardan oluşmaktadır. Bu ürünler atom üstüne atom koyarak ya da mevcut maddelerin moleküler yapısı değiştirilerek elde edilmektedir (Benli, 2008). Nanoteknolojiye duyulan ihtiyaç, toplumların refah seviyesini artırmak ve onlara daha konforlu bir yaşam sunmak amacıyla ortaya çıkmıştır (Karataş ve Ülker, 2014). Bu teknoloji ile birlikte daha az enerji kullanarak küçük, kullanışlı ve dayanıklı malzemeler üretmek amaçlamıştır. Nanoteknolojiye karşı ilginin artması, birçok disiplin alanının da ilgi odağı haline gelmiştir. Fizik, kimya, biyoloji, bilgisayar, malzeme bilimi, tıp, savunma, sanayi, elektronik, tekstil gibi çeşitli disiplinlerin de bu alandan etkilenmesi sonucu birçok çalışmalar ortaya konulmuştur (Porter ve Youtie, 2009). Özellikle fen bilimleri ve mühendisliğin yoğun ilgisiyle gelişen ve ilerleyerek diğer bilim dallarını da etkileyen bu teknoloji, günlük hayatın her alanında karşımıza çıkmaktadır. En sık rastlanılan otomotiv ve 
tıp alanındaki çalışmalar, bu muazzam küçük parçaların aslında ne kadar büyük işlevleri yerine getirdiğini göstermektedir (Whatmore, 2006). Günlük hayatta Nanoteknolojinin uygulama alanları; bilgisayar teknolojileri, geliştirilen nano hafızalar, havacılık ve uzay çalışmalarında yeni roket ve uçak tasarımı, sağlık sektöründe nano aygıtlar, savunma sanayide hafif ve gelişmiş silahlar, gıda, elektronik, dayanıklı ve paslanmayan eşyalar, tekstilde ıslanmayan ve kendi kendini temizleyebilen giysiler olarak sayılabilir (Wei ve Yan, 2016). Bu teknolojinin hayatımızın her alanında yer almasının birçok sebepleri vardır. Daha az maliyet ile daha çok üretim yapılması, ürün kalitesini yükseltmesi, enerji maliyetlerini düşürmesi ve yaşam kalitemizi arttırması gibi yararları göz önünde bulundurulduğunda bu teknolojinin gerekliliği de ortaya çıkmaktadır (Ateş \& Üce, 2017). Bu sebeple eğitimcilerin özellikle nanoteknoloji farkındalığı konusunda yeterli bilgi donanımına sahip olmaları bir ihtiyaç olarak karşımıza çıkmaktadır. İlköğretimden itibaren bu alanda eğitim verilmesi ile birlikte daha nitelikli bir insan gücü yetiştirilebilir.

Literatürdeki çalışmalar incelendiğinde, ülkemizde ne yazık ki nanoteknoloji eğitimi konusunda eksiklikler görülmektedir (Karataş \& Ülker, 2014). Bu konuya sadece Ortaöğretim Kimya Öğretim Programı 12. sınıf 4. ünitede tek bir kazanım halinde yer verilmiştir (MEB, 2018). Nanoteknoloji konusuyla ilgili yapılan çalışmalar, daha çok fen bilimleri (fizik, kimya, biyoloji, fen bilgisi) dersini alan öğrencilerin ve bu bölümleri okuyan öğretmen adaylarının farkındalık düzeylerini belirleme yönündedir (Sheetza, Vidalb, Pearsonc \& Lozano, 2005; Ekli, 2010; Farshchi, Sadrnezhaad, Nejad, Mahmoodi \& Abadi, 2011; Şenocak, 2014). Öğrencilerin bu konuda sahip olduğu bilgiye doğru bir şekilde katkıda bulunmak ya da yanlış bildiklerini gidermeye yönelik çalışmalar (O'Conor \& Hayden, 2008) pek fazla değildir. Bu çalışmanın gerçekleştirilme nedeni, fen okuryazarı bireylerin yetiştirilerek bilimsel ve teknolojik okuryazarlığın daha kaliteli bir şekilde anlaşılmasına ve ilerlemesine (Aslan \& Şenel, 2015) katkı sağlamaktır.

Fen eğitiminde öğrencilerin düşünme, sorgulama, tartışma, sentezleme gibi özellikleri kullanabileceği yöntemler tercih edilmektedir. Bağlam temelli öğrenme yaklaşımı, özellikle anlaşılması zor olan fen konularının günlük hayatla bağdaştırılarak öğrencilerin öğrenmelerinden kendilerinin sorumlu olduğu bir öğretim şeklidir (Demircioğlu, 2008). Bağlam temelli öğrenme yaklaşımın, nanoteknoloji konusunun öğretimi için tercih edilmesinin en önemli nedeni, konunun uygulama alanlarının günlük hayatla iç içe olmasıdır. Önemli olan bir diğer husus da öğretmen adaylarında nanoteknoloji farkındalığı 
oluşturarak bilgi düzeylerini arttırmak ve öğrencilerini meslek seçimi konusunda geleceğin teknolojisi olan bu alana yönlendirebilmelerine yardımcı olmaktır (Enil \& Köseoğlu, 2016). $\mathrm{Bu}$ yaklaşıma dayalı olarak yapılan öğretimin, çalışmanın sonunda konunun anlaşılması yönünde yararlı olabileceği, öğrencilerin nanoteknoloji alanına yönelik farklı fikirler ortaya koyabileceği ve bu konuda çalışma yapmayı düşünen diğer araştırmacılara kaynak ve örnek bir materyal olacağ düşünülmektedir.

\section{Araştırmanın Amacı}

$\mathrm{Bu}$ çalışmanın amacı, bağlam temelli öğrenme yaklaşımına yönelik gerçekleştirilen öğretimin fen bilgisi ve kimya öğretmen adaylarının nanoteknoloji konusunu anlamaları üzerindeki etkisini tespit etmektir. Bu amaç doğrultusunda şu alt problemlere yer verilmiştir:

1) Bağlam temelli öğrenme yaklaşımın öğretmen adaylarının nanoteknoloji konusunu anlamaları üzerinde bir etkisi var mıdır?

2) 4. sınıf Fen Bilgisi ve 4. sınıf Kimya öğretmen adaylarının, nanoteknoloji konusunu anlama düzeyleri arasında bir fark var mıdır?

3) Öğretmen adaylarının bağlam temelli öğrenme yaklaşımına dayalı olarak yapılan öğretim hakkındaki görüşleri nelerdir?

\section{Yöntem}

Çalışmada yarı deneysel yöntem kullanılmıştır. Yarı deneysel araştırma yönteminde bağımsız değişkene müdahale edilerek bağımlı değişken üzerindeki etkisi araştırılır. Bu tür çalışmalarda neden sonuç ilişkisi araştııılır. Yarı deneysel yöntem, araştırmacıların zaman kaybetmeden var olan gruplarla uygulama yapabilmelerine olanak sağlar (Plano Clark, \& Creswell, 2015). Bu çalışmada bir öğrenme yaklaşımının başka bir öğrenme yaklaşımı ile ilgili bir karşılaştırması yapılmamıştır. Aynı öğrenme yaklaşımının farklı programlarda öğrenim gören öğrencilerin aynı konu ile ilgili anlamaları üzerindeki etkisi araştırılmıştır. Her iki programda aynı uygulamalar gerçekleştirilmiştir.

Örneklem

Çalışma, 2018-2019 eğitim-öğretim yılı güz döneminde Trabzon Üniversitesi Fatih Eğitim Fakültesi 4. sınıf Fen Bilgisi (21) ve 4. sınıf Kimya (10) öğretmen adayları ile yürütülmüştür. 


\section{Veri Toplama Araçları}

Nanoteknoloji Testi: Bu çalışmada kullanılacak olan testi hazırlamadan önce, ilk olarak konu hakkında literatür taraması yapılmıştır. Alpat, Uyulgan, Şeker ve Gezer'in (2017) nanoteknoloji ile ilgili çalışmalarında kullandıkları testten yararlanılarak 7 açık uçlu sorudan oluşan bir test hazırlanmıştır. Soruların bilimsel geçerliğini sağlamak için lisans ve lisansüstü düzeyde eğitim veren iki kimya ve iki fen bilgisi eğitimcisinin görüşlerine başvurulmuştur. Testin Cronbach's alfa katsayısı 0,85 olarak bulunmuştur. Çalışmada kullanılan test Ek 3'de verilmiştir.

Anket: Kimya ve Fen Bilgisi öğretmen adaylarının, bağlam temelli öğrenme yaklaşımı ve bu yaklaşıma dayalı olarak yapılan etkinlikler hakkında görüşlerini almak için sorudan oluşan bir anket hazırlanmıştır. Anket soruları bulgular kısmında yer almaktadır. Anket, her iki gruba da son testin hemen arkasından verilmiştir.

\section{Uygulama Süreci}

Çalışma, kimya grubu ile 4 saat ve fen bilgisi grubu ile 4 saat olmak üzere toplam 8 saat yürütülmüştür. Test, uygulamaya başlamadan 2 hafta önce her iki gruba ön test, uygulama bittikten 1 hafta sonra her iki gruba son test olarak uygulanmıştır.

Öğrencilerin testteki soruları cevaplayabilmeleri için yaklaşık olarak 30 dakika süre verilmiştir. Nanoteknoloji konusunda öğrencilerin bilgi sahibi olması istenen kazanımlara uygun bir plan çizilmiştir. Kazanımlar içerisinde yer alan nanoteknolojinin tanımı, ilgili bilim dalları, kullanım amaçları, günlük hayatla ilişkisi, yararları, zararları ve toplum-çevre üzerindeki etkisi ile ilgili hikâye, belgesel ve çalışma yaprağı kullanılmıştır. Konunun her bir içeriği ile ilgili hazırlanan materyaller, bağlam temelli yaklaşımda Watters (2004) tarafından kullanılan öğretimsel tasarım dikkate alınarak öğrencilere sunulmuştur. Bu tasarım 4 aşamadan oluşmaktadır:

Giriş Aşaması: Bu aşamada, öğrencilere günlük hayatla ilişkili ve dikkat çekici sorular yöneltilerek cevap alınması ve bir tartışma ortamı sağlanması amaçlanır. Bu çalışmada da nanoteknolojinin tanımı, ilgilendiği bilim dalları ve günlük hayatla ilişkisine dayalı olarak hazırlanan senaryo öğrencilere dağıtılmıştır. Öncelikle öğrencilerden konu ile ilgili anahtar kavramları bulmaları istenmiştir. Ardından yöneltilen sorulara cevaplar alınarak bir tartışma ortamı oluşturulmuştur. Nanoteknoloji ile ilgili senaryo Ek 1'de verilmiştir.

Merak ve Planlama Aşaması: $\mathrm{Bu}$ aşamada, öğrencilere konu ile ilgili belgesel izletilmiştir. Nanoteknolojinin kullanım amaçları, yararları, zararları ve toplumlar 
üzerindeki etkisi ile ilgili olan belgeselin (https://youtu.be/mF6_jIKOm60) ardından, öğrencilerden günlük hayattan örnekler vermeleri istenmiştir. Böylece onları da konu hakkında düşünme sürecine dâhil ederek, ilgi uyandırılmaya çalışılmıştır.

Gelişme Aşaması: Bu aşamada, öğrencilere çalışma yaprağı dağıtılmış ve etkinliği yapmaları istenmiştir. Etkinlik sonunda, çalışma yaprağında yer alan sorulara bireysel olarak cevap vermeleri istenmiştir. Burada amaç, öğrencilerin tartışlan bilgileri anlamlandırabilmesini sağlamaktır. Lotus etkili yüzeyler ile ilgili olan bu etkinliğin amacı, nano yapıya sahip bu yüzeylerden günlük hayatta nasıl ve nerede yararlanıldığını göstermektir. Çalışma yaprağı Ek 2' de verilmiştir.

İlişkileri Kurma Aşaması: Bu aşamada, öğrencilerden sunulan hikâye, izletilen belgesel ve yaptırılan etkinlik sonunda elde ettikleri bilgiler ile nanoteknolojiyi anlamaları ve aralarında ilişki kurmaları beklenmiştir. Öğrencilere, "Siz bu alanda çalışıyor olsaydınız, nasıl bir ürün ortaya koymak isterdiniz?" sorusu yöneltilmiş ve cevaplar yazılı olarak alınmıştır. Öğrencilerin eksiklikleri araştırmacı tarafından tamamlanarak, ders bitirilmiştir.

Verilerin Analizi

Nanoteknoloji testindeki sorular Tablo 1'de belirtilen değerlendirme ölçütü doğrultusunda analiz edilmiştir. Abraham, Williamson ve Westbrook (1994) tarafından önerilen bu ölçüt doğrultusunda bir öğrencinin testten alabileceği en yüksek puan 21 olarak hesaplanmıştır. Açık uçlu sorulardan elde edilen veriler, frekans ve yüzde dağılımları şeklinde bulgular kısmında sunulmuştur. Ön ve son testlerden elde edilen veriler ise, gruplar arasında bağımsız t-testi ve grup içinde bağımlı t-testi kullanılarak analiz edilmiştir.

Tablo 1. Açık uçlu soruların analizinde kullanılan değerlendirme ölçütü

\begin{tabular}{cclc}
\hline $\begin{array}{c}\text { Anlama } \\
\text { Dereceleri }\end{array}$ & Kod & \multicolumn{1}{c}{ Puanlama Kriterleri } & Puan \\
\hline Tam Anlama & TA & Geçerli cevabın tamamını içeren cevaplar & 3 \\
\hline Kısmen Anlama & KA & Geçerli cevabın en az bir kısmını içeren cevaplar & 2 \\
\hline $\begin{array}{c}\text { Alternatif } \\
\text { Kavram }\end{array}$ & AK & $\begin{array}{l}\text { Olayı açılamaya çalışan ancak bilimsel fikirlerle uyuşmayan } \\
\text { cevaplar }\end{array}$ & 1 \\
\hline Boş & B & Cevapsız & 0 \\
\hline
\end{tabular}

Anketten elde edilen veriler öğrencilerin, uygulama sürecinde kullanılan yaklaşım hakkındaki görüşlerini yansıtmaktadır. Öğrenci cevapları genel olarak değerlendirilmiş ve elde edilen veriler bulgular kısminda sunulmuştur. 


\section{Bulgular}

Bu kısımda ön test, son test ve anketten elde edilen bulgular sunulmuştur.

Ön Test ve Son Testten Elde Edilen Bulgular

Kimya ve Fen Bilgisi öğretmen adaylarının başarı testi sonuçlarının ön test verilerine yönelik frekans ve yüzde dağılımları Tablo 2' de verilmiştir.

Tablo 2. Ön test verilerine yönelik frekans ve yüzde dağılımları

\begin{tabular}{cccccccccc}
\hline & & \multicolumn{2}{c}{ TA } & \multicolumn{2}{c}{ KA } & \multicolumn{1}{c}{ AK } & \multicolumn{3}{c}{ B } \\
\cline { 2 - 11 } & & f & \% & f & \% & f & \% & f & \% \\
\hline 1 & Kimya & 1 & 10 & 4 & 40 & 4 & $\mathbf{4 0}$ & 1 & 10 \\
& Fen & 6 & 28.57 & 8 & $\mathbf{3 8 . 0 9}$ & 6 & 28.57 & 1 & 4.76 \\
\hline 2 & Kimya & 1 & 10 & 2 & 20 & 5 & $\mathbf{5 0}$ & 2 & 20 \\
& Fen & 7 & 33.33 & 6 & 28.57 & 4 & 19.04 & 4 & 19.04 \\
\hline 3 & Kimya & 0 & 0 & 6 & $\mathbf{6 0}$ & 3 & 30 & 1 & 10 \\
& Fen & 1 & 4.76 & 15 & $\mathbf{7 1 . 4 2}$ & 4 & 19.04 & 1 & 4.76 \\
\hline 4 & Kimya & 0 & 0 & 1 & 10 & 6 & $\mathbf{6 0}$ & 3 & 30 \\
& Fen & 0 & 0 & 2 & 9.52 & 12 & 57.14 & 7 & 33.33 \\
\hline 5 & Kimya & 0 & 0 & 2 & 20 & 3 & 30 & 5 & $\mathbf{5 0}$ \\
& Fen & 0 & 0 & 7 & 33.33 & 5 & 23.80 & 9 & $\mathbf{4 2 . 8 5}$ \\
\hline 6 & Kimya & 0 & 0 & 2 & 20 & 0 & 0 & 8 & $\mathbf{8 0}$ \\
& Fen & 0 & 0 & 2 & 9.52 & 5 & 23.80 & 14 & $\mathbf{6 6 . 6 6}$ \\
\hline 7 & Kimya & 0 & 0 & 3 & 30 & 1 & 10 & 6 & $\mathbf{6 0}$ \\
& Fen & 0 & 0 & 3 & 14.28 & 3 & 14.28 & 15 & $\mathbf{7 1 . 4 2}$ \\
\hline
\end{tabular}

Tablo 2'de görüldüğü gibi, Kimya ve Fen Bilgisi öğretmen adayları 1 ve 2. soruları "Kısmen Anlama” kategorisinde yapabilmişlerdir. Kimya öğretmen adayları hiçbir soruyu "Tam Anlama" kategorisinde yapamamıştır. Fen Bilgisi öğretmen adayları 2. soruyu \%33.33 oranında "Tam Anlama" kategorisinde yapabilmiştir. Genel olarak bakıldığında öğretmen adaylarının "Alternatif Kavram" ve "Boş" kategorileri oranlarının diğer kategorilere göre daha yüksek olduğu görülmektedir.

Kimya ve Fen Bilgisi öğretmen adaylarının başarı testi sonuçlarının son test verilerine yönelik frekans ve yüzde dağılımları Tablo 3'de verilmiştir.

Tablo 3. Son test verilerine yönelik frekans ve yüzde dağılımları

\begin{tabular}{|c|c|c|c|c|c|c|c|c|c|}
\hline & & \multicolumn{2}{|c|}{ TA } & \multicolumn{2}{|c|}{ KA } & \multicolumn{2}{|c|}{ AK } & \multicolumn{2}{|c|}{ B } \\
\hline & & $\mathbf{f}$ & $\%$ & $f$ & $\%$ & $\mathbf{f}$ & $\%$ & $f$ & $\%$ \\
\hline \multirow[t]{2}{*}{1} & Kimya & 8 & 80 & 0 & 0 & 2 & 20 & 0 & 0 \\
\hline & Fen & 11 & 52.38 & 9 & 42.85 & 0 & 0 & 1 & 4.76 \\
\hline \multirow[t]{2}{*}{2} & Kimya & 5 & 50 & 4 & 40 & 1 & 10 & 0 & 0 \\
\hline & Fen & 8 & 38.09 & 12 & 57.14 & 0 & 0 & 1 & 4.76 \\
\hline \multirow[t]{2}{*}{3} & Kimya & 3 & 30 & 6 & 60 & 1 & 10 & 0 & 0 \\
\hline & Fen & 10 & 47.61 & 10 & 47.61 & 1 & 4.76 & 0 & 0 \\
\hline \multirow[t]{2}{*}{4} & Kimya & 3 & 30 & 5 & 50 & 2 & 20 & 0 & 0 \\
\hline & Fen & 8 & 38.09 & 10 & 47.61 & 1 & 4.76 & 2 & 9.52 \\
\hline 5 & Kimya & 2 & 20 & 7 & 70 & 1 & 10 & 0 & 0 \\
\hline
\end{tabular}


Demircioğlu \& Özdemir

\begin{tabular}{cccccccccc}
\hline & Fen & 7 & 33.33 & 11 & $\mathbf{5 2 . 3 8}$ & 0 & 0 & 3 & 14.28 \\
\hline 6 & Kimya & 3 & 30 & 4 & $\mathbf{4 0}$ & 2 & 20 & 1 & 10 \\
& Fen & 3 & 14.28 & 14 & $\mathbf{6 6 . 6 6}$ & 0 & 0 & 4 & 19.04 \\
\hline 7 & Kimya & 0 & 0 & 8 & $\mathbf{8 0}$ & 0 & 0 & 2 & 20 \\
& Fen & 2 & 9.52 & 12 & $\mathbf{5 7 . 1 4}$ & 2 & 9.52 & 5 & 23.80 \\
\hline
\end{tabular}

Tablo 3'de görüldüğü gibi, Kimya ve Fen Bilgisi öğretmen adayları sorulara “Tam Anlama" ve "Kısmen Anlama" kategorilerinde cevap verebilmişlerdir. Kimya ve Fen Bilgisi öğretmen adayları "Alternatif Kavram" kategorisinde de düşük oranda cevaplar vermişlerdir. Kimya öğretmen adayları 6 ve 7. sorular dışında hiçbir soruyu boş bırakmamıştır. Fen Bilgisi öğretmen adayları sadece 3. soruyu boş bırakmamıştır.

Kimya ve Fen Bilgisi öğretmen adaylarının ön test verilerine yönelik bağımsız t-testi sonuçları Tablo 4'te verilmiştir.

Tablo 4. Kimya ve Fen Bilgisi öğretmen adaylarının ön test verilerine yönelik bağımsız t-testi sonuçları

\begin{tabular}{|c|c|c|c|c|c|c|}
\hline Gruplar & $\mathbf{N}$ & Ortalama & Std. Sapma & df & $\mathbf{t}$ & p \\
\hline Kimya & 10 & 6,800 & 3,259 & \multirow{2}{*}{29} & \multirow{2}{*}{2,045} & \multirow{2}{*}{0,535} \\
\hline Fen & 21 & 7,428 & 2,248 & & & \\
\hline
\end{tabular}

Tablo 4'te görüldüğü gibi, kimya ve fen bilgisi öğretmen adaylarının ön testten elde ettikleri ortalamalar arasındaki fark istatistiksel olarak anlamlı bulunmamıştır $(t(29)=2,045$; p>0,05). Buradan grupların çalışılan konu ile ilgili ön bilgilerinin denk olduğu anlaşılmaktadır. Kimya ve Fen Bilgisi öğretmen adaylarının son test verilerine yönelik bağımsız t-testi sonuçları Tablo 5'te verilmiştir.

Tablo 5. Kimya ve Fen Bilgisi öğretmen adaylarının son test verilerine yönelik bağımsız t-testi sonuçları

\begin{tabular}{|c|c|c|c|c|c|c|}
\hline Gruplar & $\mathbf{N}$ & Ortalama & Std. Sapma & df & $t$ & $\mathrm{p}$ \\
\hline Kimya & 10 & 14,900 & 2,960 & \multirow{2}{*}{29} & \multirow{2}{*}{2,045} & \multirow{2}{*}{0,859} \\
\hline Fen & 21 & 14,619 & 4,510 & & & \\
\hline
\end{tabular}

Tablo 5'te görüldüğü gibi, kimya ve fen bilgisi öğretmen adaylarının son testten elde ettikleri ortalamalar arasındaki fark istatistiksel olarak anlamlı bulunmamıştır $(t(29)=2,045$; p>0,05). Buradan konunun öğretiminde kullanılan yaklaşımın iki grup için de etkili olduğu görülmektedir. Kimya ve Fen Bilgisi öğretmen adaylarının ön test ve son test verilerine yönelik bağımlı t-testi sonuçları Tablo 6'da verilmiştir.

Tablo 6. Kimya ve Fen Bilgisi öğretmen adaylarının ön test ve son test verilerine yönelik bağımlı ttesti sonuçları

\begin{tabular}{|c|c|c|c|c|c|c|}
\hline Gruplar & & $\mathbf{N}$ & Ortalama & Std. Sapma & $\mathrm{df}$ & $\mathrm{p}$ \\
\hline \multirow{2}{*}{ Kimya } & Ön test & 10 & 6,800 & 3,259 & \multirow{2}{*}{9} & \multirow{2}{*}{0,000} \\
\hline & Son test & 10 & 14,900 & 2,960 & & \\
\hline \multirow{2}{*}{ Fen bilgisi } & Ön test & 21 & 7,428 & 2,248 & \multirow{2}{*}{20} & \multirow{2}{*}{0,000} \\
\hline & Son test & 21 & 14,619 & 4,510 & & \\
\hline
\end{tabular}


Tablo 6'da görüldüğü gibi, bağımlı t-testi analizi sonucunda ön test puanları ile son test puanları arasındaki farkın istatistiksel olarak son test lehine anlamlı olduğu belirlenmiştir $(\mathrm{p}<0,05)$. Buradan konunun öğretiminde kullanılan yaklaşımın kimya ve fen bilgisi öğretmen adayları için etkili olduğu görülmektedir.

Anketten Elde Edilen Bulgular

Anketten elde edilen veriler Cohen ve Manion (1989) önerdikleri şekilde, puanlandırma yapılmaksızın öğrencilerin verdikleri cevaplar genel bir özet şeklinde sunulmuştur.

1) Nanoteknoloji konusunda yapılan etkinlikler (hikâye, belgesel, çalışma yapră̆ı), konunun anlaşılması açısından yararlı oldu mu? Açıklayınız.

Fen grubu öğrencileri genel olarak yapılan etkinliklerin yararlı olduğunu ve soyut bir konunun bu şekilde somutlaştırılıp anlatılabileceğini hiç düşünmediklerini belirtmişlerdir. Kimya grubu öğrencileri de özellikle belgesel ve çalışma yaprağının çok yararlı olduğunu belirtmişlerdir. Kimya grubundan bir öğrenci izletilen belgesele benzer bir video izlediği için, belgeselin çok fazla bir etkisinin olmadığını belirtmiştir.

2) Nanoteknoloji eğitimi sizce ilköğretimden itibaren mi verilmeye başlanmalıdır? Neden?

Fen grubu öğrencilerinin çoğunluğu, farkındalığın küçük yaştan itibaren sağlanabilmesi için ilköğretimden itibaren bu eğitimin verilmesi gerektiğini belirtmişlerdir. 5 öğrenci ise, ilkokul döneminin çok erken olduğunu ve bu yüzden ortaöğretimden itibaren bu konu hakkında eğitim verilmesi gerektiğini belirtmişlerdir. Kimya grubu öğrencilerinin yarısı gelişen teknolojiye uyum sağlanabilmesi için bu eğitimin ilkokuldan itibaren verilmesi gerektiğini belirtmişlerdir. Diğer yarısı ise, ilköğretim seviyesindeki bir öğrencinin nanoteknolojiyi anlayabilecek düzeyde olmadığını ve ortaöğretimin daha uygun olabileceğini belirtmişlerdir.

3) Bağlam temelli öğrenme yaklaşımına dayalı olarak işlenen ders nanoteknoloji konusunun öğrenilmesinde etkili oldu mu? Etkili oldu ise hangi boyutlarda etkili oldu? Açıklayınız.

Kimya ve fen grubu öğrencileri bağlam temelli yaklaşıma yönelik yürütülen dersin etkili olduğunu belirtmişlerdir. Konunun materyallerle desteklenerek, günlük hayattan örnekler verilmesinin soyut olan bu konunun somut hale getirilip anlaşılmasında ve öğrencinin öğrenme sürecinde aktif kılınmasında yararlı olduğunu belirtmişlerdir.

4) Nanoteknoloji hakkında önceki ve şimdiki bilgileriniz arasında bir fark var mı? Varsa bunlar neler? Açıklayınız. 
Kimya ve fen grubu öğrencileri, önceki ve şimdiki bilgileri arasında farklar olduğunu belirtmişlerdir. Bu farkın daha çok nanoteknolojinin kullanım alanına yönelik olduğunu ve günlük hayatın her alanında olduğunu öğrendiklerini belirtmişlerdir. Kimya grubundan bir öğrenci, bu konuyu önceden bildiğini ve bu yüzden bilgileri arasında çok bir fark olmadığını belirtmiştir.

\section{Tartışma ve Sonuç}

Yarı deneysel yöntemin kullanıldığı bu çalışmada, kimya ve fen gruplarının ön testson test başarı testi sonuçlarını karşılaştırdığımızda son testte her iki grubun ortalamalarının arttığı görülmüştür. Bu durum çalışmada kullanılan bağlam temelli öğrenme yaklaşımının etkili olduğunu göstermektedir.

Literatürde de bağlam temelli öğrenme yaklaşımına dayalı olarak gerçekleştirilen birçok çalışmada bu yaklaşımın öğrencilerde anlamayı artırmaya yardımcı olduğuna yönelik bulgular mevcuttur (Yager \& Weld, 1999; Tsai, 2000; Holman \& Pilling, 2004; Demircioğlu, Demircioğlu \& Çalık, 2009; Ültay \& Çalık, 2012; Demircioğlu, Dinç \& Çalık, 2013; Demircioğlu, Ayas, Demircioğlu \& Özmen, 2015; Demircioğlu, Bektaş \& Demircioğlu, 2018; Demircioğlu, Aşık \& Yılmaz, 2019). O'Connor ve Hayden (2008) tarafından yapılan bağlam temelli öğrenme yaklaşımına dayalı olarak gerçekleştirilen nanoteknoloji öğretiminin öğrencilerin anlamalarını artırdı̆̆ını göstermiştir.

Tablo 2'de görüldüğü gibi ön testte her iki grup öğrencileri de nanoteknoloji kavramı, kullanım amaçları, kullanıldığı bilim dalları ile ilgili sorular için "tam anlama" ve "kısmen anlama" kategorilerinde cevaplar vermişlerdir. Ancak nanoteknolojinin günlük hayatla ilişkisi, yararları, zararları, toplum ve çevre üzerindeki etkisi ile ilgili soruları cevapsız bırakmışlar veya "alternatif kavram" kategorisinde cevap vermişlerdir. İki grubun da sorulara verdiği cevaplara bakıldığında, yüzde oranlarının en fazla olduğu kategoriler "kısmen anlama", "alternatif kavram" ve "boş" kategorileridir. Başarı testi ön test sonuçlarından anlaşıldığı gibi, iki grup öğrencileri de nanoteknoloji konusunda yeterli düzeyde bilgiye sahip değildir. Özellikle nanoteknoloji konusunun öğretilmesinde en önemli rolü oynayacak olan öğretmen adaylarının bu konu hakkındaki bilgilerinin sınırlı olması ciddi bir problemdir. Bu sebeple öğretmen adaylarının farkındalıklarını artırmanın son derece önemli olduğu, bu alanda yapılan çalışmalarda ortaya çıkmıştır (Enil \& Köseoğlu, 2016). 
Tablo 3’de görüldüğü gibi, son testte kimya ve fen bilgisi öğretmen adayları sorulara "tam anlama" ve "kısmen anlama" kategorilerinde cevaplar verebilmişlerdir. Kimya öğretmen adayları 6 ve 7.sorular dışında hiçbir soruyu boş bırakmamıştır. Fen bilgisi öğretmen adayları sadece 3.soruyu boş bırakmamıştır. Kimya ve Fen Bilgisi öğretmen adaylarının ön testte ve son testte başarı testine vermiş oldukları cevapları karşılaştırdığımızda, olumlu yönde bir gelişme olduğu görülmektedir. Ön testte daha çok “alternatif kavram" ve "boş" kategorilerinde cevaplar veren öğrencilerin, son testte daha çok “tam anlama” ve "kısmen anlama" kategorilerinde cevaplar verdiği görülmektedir. Ön testte "boş" kategorisinde yüksek oranlara sahip olan 5, 6 ve 7. sorular, son testte "kısmen anlama" kategorisinde yüksek oranlarda yer almaktadır.

Başarı testi son test sonuçlarından anlaşıldığı gibi, bağlam temelli öğrenme yaklaşımına yönelik yürütülen nanoteknoloji konusunun öğretimi ile her iki grubun da akademik başarı düzeyleri artmıştır. Bağlam temelli öğrenme yaklaşımına dayalı olarak geliştirilen ve konunun öğretiminde kullanılan materyallerin, etkinliklerin ilgi çekici ve motive edici olması öğrencilerin öğrenmelerine katkı sağladığı literatürde yer alan çalışmalarda da (Demircioğlu, 2008; O'Connor \& Hayden, 2008; Demircioğlu, 2012; Demircioğlu, Dinç \& Çalık, 2013; Demircioğlu, Ayas, Demircioğlu \& Özmen, 2015; Elmas ve Geban, 2016; Gül, Gürbüzoğlu Yalmanc1 \& Yalmanc1, 2017; Karslı \& Yiğit, 2017; Kirman Bilgin \& Yiğit, 2017; Demircioğlu, Bektaş \& Demircioğlu, 2018; Gül \& Konu, 2018; Demircioğlu, Aşık \& Yılmaz, 2019) ifade edilmektedir.

Bağlam temelli öğrenme yaklaşımına yönelik yürütülen çalışmalar incelendiğinde, özellikle öğrenilmesi zor ve soyut olan konuların öğretiminde bu yaklaşımın kullanılması ile birlikte öğrenmenin daha eğlenceli olduğunu belirttikleri ortaya çıkmıştır (Ramsden, 1997; Reid, 2000; Banister \& Ryan, 2001; Demircioğlu, 2008; Kutu \& Sözbilir, 2011; Topuz, Gencer, Bacanak \& Karamustafaoğlu, 2013; Karslı \& Yiğit, 2015; Yıldırım \& Gültekin, 2017; Demircioğlu, Bektaş \& Yılmaz, 2018; Demircioğlu, Aşık \& Yılmaz, 2019). Elde edilen anket verileri de bu görüşü desteklemektedir. Özellikle anlaşılması zor ve soyut olan nanoteknoloji konusunun günlük hayatla bağdaştırılarak öğretimi öğrencilerde ilgi uyandırmış ve anlamalarını kolaylaştırmıştır.

Anket sonuçlarına genel olarak bakıldığında, her iki grup da ders sürecinde kullanılan materyallerin konunun anlaşılmasında yararlı olduğunu düşünmektedir. Öğrenciler soyut olan nanoteknoloji konusunun izletilen belgesel, dağıtılan hikâye ve 
çalışma yaprağı ile birlikte somutlaştırılarak öğrenmenin daha kolay ve zevkli hale geldiğini belirtmişlerdir. Her iki grupta da belgesel ve çalışma yaprağı daha çok dikkat çekmiştir. Öğretimde belgesellerin (Öztaş, 2008; Barak \& Dori, 2011; Seçkin-Kapucu, 2013) ve çalışma yapraklarının (Hand \& Treagust, 1991; Demircioğlu, Demircioğlu \& Ayas, 2004; Demircioğlu, Akdeniz \& Demircioğlu, 2004; Atasoy, 2008; Yeşilyurt \& Gül, 2011) kullanılmasının öğrencilerin ilgi ve motivasyonlarını artırdığı yapılan farklı çalışmalarda da görülmektedir.

Nanoteknoloji eğitiminin ilköğretimden itibaren verilmeye başlanmasıyla ilgili öğrenci görüşleri farklılık göstermektedir. Her iki grup öğrencilerinin bir kısmı ortaöğretimden itibaren verilmesinin daha uygun olabileceğini belirtirken, bir kısmı da ilköğretim daha iyi olabileceğini belirtmiştir. Gerekçe olarak ilköğretimin çok erken olduğu, nanoteknoloji konusunun o seviyedeki öğrenciler için anlaşılmasının zor olduğunu söylemişlerdir. Atabaş (2012) tarafından ilköğretim düzeyindeki öğrencilerle gerçekleştirilen çalışmanın sonucunda öğrencilerin konuyu ilgi çekici bulduğu ve konuyu öğrenmede zorluk çekmedikleri belirlenmiştir. Bu alanda yapılan çalışmalarda fen okuryazarlığı ile birlikte, nano okuryazarlığının da gerekli olduğu ortaya çıkmıştır. Ancak bu eğitimin erken yaşlarda verilmesiyle birlikte bilimsel okuryazarlığa sahip bireylerin yetişebileceği düşünülmektedir (Aslan \& Şenel, 2015).

Nanoteknoloji konusunda bağlam temelli öğrenme yaklaşımına yönelik gerçekleştirilen öğretimin, öğrenme üzerinde etkililiği hakkında her iki grup öğrencileri de aynı fikre sahiptir. Öğrenciler, günlük hayatla ilişkili etkinliklere yer verilmesinin konunun anlaşılması açısından yararlı olduğunu söylemişlerdir. Yapılan çalışmalar, günlük hayatla ilişkilendirmelerin öğrencilerin kavramları anlamasını kolaylaştırdığını göstermiştir (Choi \& Johnson, 2005; Demircioğlu, Vural ve Demircioğlu, 2012; Demircioğlu, Ayas, Demircioğlu ve Özmen, 2015; Elmas \& Geban, 2016; Karslı \& Yiğit, 2017; Demircioğlu, Bektaş \& Yılmaz, 2018; Gül \& Konu, 2018; Demircioğlu, Aşık \& Yılmaz, 2019). Bağlam temelli öğrenme yaklaşımında amaç; öğrencilerin günlük hayatta sıklıkla karşılaşabilecekleri bilimsel kavramları sorgulayarak, onları araştırma yapmaya yönlendirmektir. Böylece öğrenmelerinden kendileri sorumlu olacaklardır (Demircioğlu, 2008). 


\section{Öneriler}

Nanoteknoloji farkındalığını ve öğrencilerin bu konu ile ilgili anlamalarını artırmak için yapılacak olan çalışmalarda kullanılacak olan etkinlikler çok iyi seçilmelidir. Özellikle öğrencilerin zihinlerinde kalıcı olabilecek, somut örnekler öğrencilere sunulmalıdır ve yeni yanlış anlamaların oluşmaması için özen gösterilmelidir. Nanoteknoloji sayesinde sanayide, bilişim teknolojilerinde, savunma, malzeme, sağlık sektöründe ve daha birçok alanda yeni ürünler geliştirilecek, günümüzün üretim süreçleri ve yöntemleri değişecektir. Bu teknolojiye yatırım yapılan ülkelerde ekonomik değerler çeşitlendirilebilecek ve bu da toplumların yaşam kalitesini geliştirecektir (URL-3). Bu yüzden bu alanda çalışabilecek bireylere ilk elden ulaşabilecek olan öğretmen adaylarının farkındalıklarının artırılması, doğru bir şekilde bilgilendirilmesi son derece önemlidir. Bu çalışmada öğrencilerin senaryo hakkında pek bir görüş belirtmediği ortaya çıkmıştır. Senaryoların okunması öğrenciler için sıkıcı bir durum olabilir. Daha zevkli hale getirilebilmesi için, bilgisayar destekli materyaller (animasyon, vb.) kullanilabilir.

$\mathrm{Bu}$ çalışmada bağlam temelli öğrenme yaklaşımın, uygulama ve öğretimde etkili olduğu görülmüştür. Özellikle öğrenciler için zor ve sıkıcı olarak görülen fen bilimleri dersinde (fizik, kimya ve biyoloji), bu yaklaşımın kullanılması ilgi uyandırıcı olabilir. Öğrencilerin konuları öğrenmesinde ve günlük hayatla ilişkilendirebilmesinde yararlı olabileceği düşünülmektedir. Bu yüzden öğretmenler bu yaklaşımı kullanmaktan çekinmemeli ve zaman kaybı olarak görmemelidir.

Gelecekte öğretmen olacak adayların bu çalışmanın içerisinde yer alarak, birebir bağlam temelli öğrenme yaklaşımının öğrenme ortamında nasıl kullanıldığına dair dikkate değer bir deneyim kazanmış olmaları da son derece önemlidir. Stolk, Bulte, de Jong ve Pilot (2009a; 2009b) tarafından belirtildiği gibi öğretmen adayları bu sayede yeni yaklaşımların tasarlanması ve uygulanması konusunda birinci elden pratik deneyim kazanmış oldular. Bu sayede ileride öğrencilerinin aktif olarak katılabilecekleri zenginleştirilmiş öğrenme ortamları hazırlayabilirler.

\section{Bilgilendirme}

Bu çalışma, 25-28 Nisan 2019 tarihleri arasında gerçekleştirilen XII. Uluslararası Eğitim Araştırmaları Kongresi'nde sözlü bildiri olarak sunulmuştur. 


\section{Kaynaklar}

Abraham, M. R., Williamson, V. M. \& Westbrook, S. L. (1994). A cross-age study of the understanding of five chemistry concepts. Journal of Research in Science Teaching, 31(2), 147-165.

Aktan, C. C. \& Vural, İ. Y. (2016). Bilgi toplumu, yeni temel teknolojiler ve yeni ekonomi. Bilim ve Teknoloji Özel Sayısı, 1(88).

Allhoff, F., Lin, P. \& Moore, D. (2010). What is nanotechnology and why does it matter?: from science to ethics, United Kingdom: Wiley-Blackwell Publication.

Alpat Kılınç, S., Uyulgan, M. A., Şeker, S., Altaş, H. Ş. \& Gezer, E. (2017). Effect of cooperative learning on academic achievement and opinions of the $10^{\text {th }}$ grade students' in the topic of nanotechnology at secondary level. Inonu University Journal of the Faculty of Education, 18(1), 27-57.

Aslan, O. \& Şenel, T. (2015). Fen alanları öğretmen adaylarının nanobilim ve nanoteknoloji farkındalık düzeylerinin çeşitli değişkenlere göre incelenmesi. Dicle Üniversitesi Ziya Gökalp Ĕ̆itim Fakültesi Dergisi, 24, 363-389.

Atabaş, Ü. (2012). İlköğretim öğrencilerini nanoteknoloji ve biyoteknoloji konularnnda eğitmeye ve bilgilendirmeye yönelik bir çalışma. Yüksek Lisans Tezi, Fatih Üniversitesi Mühendislik ve Fen Bilimleri Enstitüsü, İstanbul.

Atasoy, Ş. (2008). Öğretmen adaylarının newton'un hareket kanunları konusundaki kavram yanılgılarının giderilmesine yönelik geliştirilen çalışma yapraklarının etkililiğinin araştırılması. Yayımlanmamış doktora tezi, Karadeniz Teknik Üniversitesi, Fen Bilimleri Enstitüsü, Trabzon.

Ateş, İ. \& Üce, M. (2017). Lise öğrencilerinin nanobilim ve nanoteknoloji farkındalığı. Gazi Üniversitesi Gazi Ĕ̆itim Fakültesi Dergisi, 37(2), 685-710.

Banister, F. \& Ryan, C. (2001). Developing science concepts through story-telling. School Science Review, 83(302), 75-83.

Barak, M. \& Dori, Y. J. (2011). Science education in primary schools: Is an animation worth a thousand pictures?. Journal of Science Education and Technology, 20(5), 608-620.

Benli, B. (2008). Nanoteknoloji ve antik çağlara uzanan killi nanoyapılar. Kil Bilimi ve Teknoloji Dergisi, 1(3), 143-162.

Choi, H. J. \& Johnson, S. D. (2005). The effect of context-based video instruction on learning and motivation in on-line courses. The American Journal of Distance Education, 19(4), 215-227.

Cohen, L. \& Monion, L. (1990). Research methods in education, Routledge, London.

Demircioğlu H., Aşık, T. \& Yılmaz, P. (2019). REACT stratejisine dayalı öğretimin etkisi: “Su arıtımı ve suyun sertliği". International Journal of Scientific and Technological Research, 5(2), 104-118. DOI: 10.7176/JSTR/5-2-13 
Demircioğlu, H. (2008). Sinı öğretmeni adaylarına yönelik maddenin halleri konusuyla ilgili bağlam temelli materyal geliştirilmesi ve etkililiğinin araştırılması. Doktora Tezi, Karadeniz Teknik Üniversitesi, Fen Bilimleri Enstitüsü, Trabzon.

Demircioğlu, H. (2012). The effects of storylines embedded within the context-based approach on grade 10 student' conceptions of the change of states. Energy Education Science and Technology Part B: Social and Educational Studies, 4(4), 2429-2438.

Demircioğlu, H., Akdeniz, A. R. \& Demircioğlu, G. (2004, Ekim). Maddenin tanecikli yapısına ilişkin kavram yanılgılarının giderilmesinde çalışma yapraklarının etkisi. Gazi Üniversitesi Ĕ̆itim Bilimleri Enstitüsü XII. Ĕ̆gitim Bilimleri Kongresi Bildiri Kitabı (Cilt III) içinde (s.2137-2160). Ankara.

Demircioğlu, H., Ayas, A., Demircioğlu, G. \& Özmen, H. (December, 2015). Effects of storylines embedded within the context-based approach on pre-service primary school teachers' conceptions of matter and its states. Asia-Pacific Forum on Science Learning and Teaching, 16(2).

Demircioğlu, H., Bektaş, F. \& Demircioğlu, G. (2018). Sıvıların özellikleri konusunun bağlam temelli yaklaşımla öğretiminin öğrenci başarısı üzerindeki etkisi. Dicle Üniversitesi Ziya Gökalp Eğitim Fakültesi Dergisi, 33, 13-25.

Demircioğlu, H., Demircioğlu, G. \& Ayas, A. (2004). Kavram yanılgılarının çalışma yapraklarıyla giderilmesine yönelik bir çalışma. Milli Ĕ̆itim Dergisi, 163, 121-131.

Demircioğlu, H., Demircioğlu, G., \& Çalık, M. (2009). Investigating effectiveness of storylines embedded within context based approach: the case for the periodic table. Chemistry Education: Research and Practice, 10, 241-249.

Demircioğlu, H., Dinç, M. \& Çalık, M. (2013). The effect of storylines embedded within context-based learning approach on grade 6 students' understanding of 'physical and chemical change' concepts. Journal of Baltic Science Education (JBSE), 12(5), 682-691.

Demircioğlu, H., Vural, S. \& Demircioğlu, G. (2012). "REACT" stratejisine uygun hazırlanan materyalin üstün yetenekli öğrencilerin başarısı üzerinde etkisi. Ondokuz Mayıs Üniversitesi Ĕ̆itim Fakültesi Dergisi, 31(2), 101-144.

Demirtaş, M. (2011). Nanoteknoloji. https://youtu.be/mF6_jIKOm60

Ekli, E. (2010). İlköğretim ikinci kademe öğrencilerinin nanoteknoloji hakkındaki temel bilgi ve görüşleri ile teknolojiye yönelik tutumlarının bazı değişkenler açısından araştırılması. Yüksek Lisans Tezi, Muğla Üniversitesi Fen Bilimleri Enstitüsü, Muğla.

Elmas, R. \& Geban, Ö. (2016). Bağlam temelli kimya eğitiminin 9. sinıf öğrencilerinin temizlik maddeleri konusunu öğrenmelerine ve çevreye karşı tutumlarına etkisinin incelenmesi. Eğitim ve Bilim, 41(185), 33-50. DOI: 10.15390/EB.2016.5502

Enil, G. \& Köseoğlu, Y. (2016). Fen bilimleri (fizik, kimya ve biyoloji) öğretmen adaylarının nanoteknoloji farkındalık düzeyleri, ilgileri ve tutumlarının araştırılması. International Journal of Social Sciences and Education Research, 2(1), 50-63. 
Farshchi, P., Sadrnezhaad, S. K., Nejad, N. M., Mahmoodi, M. \& Abadi, L. I. G. (2011). Nanotechnology in the public eye: The case of Iran, as a developing country. Journal of Nanoparticle Research, 13(8), 3511-3519.

Gül, Ş. \& Konu, M. (2018). Yaşam temelli probleme dayalı öğretim uygulamalarının öğrenci başarısına etkisi. Yaşadıkça Eğitim, 32(1), 45-68.

Gül, Ş., Gürbüzoğlu Yalmanc1, S. \& Yalmanc1, E. (2017). Boşaltım sistemi konusunun öğretiminde REACT stratejisinin etkisi. Kastamonu Eğitim Dergisi, 25(1), 79-96.

Hand, B. \& Treagust, D. F. (1991). Student achievement and science curriculum development using a constructivist framework. School Science and Mathematics, 91(4), 172-176.

Holman, J., \& Pilling, G. (2004). Thermodynamics in context: a case study of contextualized teaching for undergraduates. Journal of Chemical Education, 81(3), 373-375.

Karataş, F.Ö. \& Ülker, N. (2014). Kimya öğrencilerinin nanobilim ve nanoteknoloji konularındaki bilgi düzeyleri. Türk Fen Ĕ̆itimi Dergisi, 11(3), 103-118.

Karslı, F. \& M. Yiğit. (2015). Effect of context-based learning approach on 12th grade students' conceptual understanding about alkanes. Inonu University Journal of the Faculty of Education 16(1), 43-62. doi: 10.17679/iuefd.16124860.

Karsl1, F. \& Yiğit, M. (2017). Effectiveness of the REACT strategy on 12th grade students' understanding of the alkenes concept. Research in Science \& Technological Education, 118. DOI: $10.1080 / 02635143.2017 .1295369$

Kirman Bilgin, A. \& Yiğit, N. (2017). Öğrencilerin "maddenin tanecikli yapısı" konusu ile bağlamları ilişkilendirme durumlarının incelenmesi. Mersin Üniversitesi Ĕ̆itim Fakültesi Dergisi, 13(1), 303-322.

Körözlü, N. (2016). Bilim ve teknolojinin geleceği: Nanoteknoloji. Göller Bölgesi Aylık Hakemli Ekonomi ve Kültür Dergisi Ayrıntı, 27-30.

Kutu, H. \& Sözbilir, M. (2011). Yaşam temelli ARCS öğretim modeliyle 9. sinıf kimya dersi “Hayatımızda Kimya” ünitesinin öğretimi. Ondokuz Mayıs Üniversitesi Eğitim Fakültesi Dergisi, 30(1), 29-62.

Milli Eğitim Bakanlığ1 [MEB], (2018). Ortaöğretim kimya dersi (9, 10, 11 ve 12. sinıflar) öğretim programi, Ankara.

O'Connor, C. M. \& Hayden, H. (2008). Contextualising nanotechnology in chemistry Education. Chemistry Education Research and Practice, 9(35), 1-29.

Öztaş, S. (2008). Tarih öğretimi ve filmler. Kastamonu Eğitim Dergisi, 16(2), 543-556.

Plano Clark, V. L. \& Creswell, J. W. (2015). Understanding research: A consumer's guide. Upper Saddle River, NJ: Pearson Education

Porter, A.L. \& Youtie, J. (2009). How interdisciplinary is nanotechnology?. Journal of Nanopart Research, 11, 1023-1041.

Ramsden, J. M. (1997). How does a context-based approach influence understanding of key chemical ideas at 16+?. International Journal of Science Education, 19(6), 697-710. 
Reid, N. (2000). The presentation of chemistry logically driven or applications-led?. Chemistry Education: Research and Practice in Europe, 1(3), 381-392.

Seçkin-Kapucu, M. (2013). Fen ve teknoloji dersinde belgesel kullanılmasının 8. sinıföğrencilerinin hücre ilekuvvet konularındaki başarılarına ve bilimin doğası hakkındaki görüşlerine etkisi. Doktora Tezi, Hacettepe Üniversitesi Sosyal Bilimler Enstitüsü, Ankara.

Sheetza, T., Vidalb, J., Pearsonc, T. D. \& Lozano, K. (2005). Nanotechnology: Awareness and societal concerns. Technology in Society, 27, 329-345.

Stolk M. J., Bulte A. M. W., de Jong O. \& Pilot A. (2009a) Strategies for a professional development programme: empowering teachers for context-based chemistry education. Chemistry Education Research and Practice, 10, 154-163.

Stolk M. J., Bulte A. M. W., de Jong O. \& Pilot A., (2009b), Towards a framework for a professional development programme: empowering teachers for context-based chemistry education. Chemistry Education Research and Practice, 10, 164-175.

Şenocak, E. (2014). A survey on nanotechnology in the view of the turkish public. Science Technology \& Society, 19(1), 79-94.

Topuz, F. G., Gençer, S., Bacanak, A. \& Karamustafaoğlu, O. (2013). Bağlam temelli yaklaşım hakkında fen ve teknoloji öğretmenlerinin görüşleri ve uygulayabilme düzeyleri. Amasya Üniversitesi Ĕ̆itim Fakültesi Dergisi, 2(1), 240-261.

Tsai C-C., (2000), The effects of STS oriented instructions on female tenth graders' cognitive structure outcomes and the role of student scientific epistemological beliefs, International Journal of Science Education, 22, 1099-1115.

Tüylek, Z. (2016). Küçük şeylerin hikâyesi: Nanomalzeme. Nevşehir Bilim ve Teknoloji Dergisi. 5(2), 130-141.

URL-1.Nanoteknoloji. https://ahmetakgonul.weebly.com/kullan305m-alanlar305.html

URL-2. Nanoteknoloji, hayatımızı kökten değiştirecek. https://www.timeturk.com/nanoteknolojihayatimizi-kokten-degistirecek/haber-935986

URL-3. Nanoteknolojinin önemi. https://ahmetakgonul.weebly.com/oumlnemi.html

Watters, J. J. (August, 2004). Engaging with chemistry through contexts. Paper presented to the Royal Australian ChemicalI enstitute, Tertiary-Secondary Interface Conference, Brisbane, Retrieved from http://eprints.qut.edu.au/archive/00006582/01/6582.pdf.

Wei, Y. \& Yan, B. (2016). Nanoproducts in daily life: To know what we do not know. National Science Review, 3, 414-415.

Whatmore, R. W. (2006). Nanotechnology-what is it? should we be worried?. Occupational Medicine, 56, 295-299.

Yager R. E. \& Weld J. D. (1999). Scope, sequence and co-ordination: The Iowa project, a national reform effort in the USA, International Journal of Science Education, 21, 169- 194.

Yeşilyurt, S. \& Gul, Ş. (2011). Yapılandırmacı öğrenme yaklaşımına dayalı hazırlanan çalışma yaprağının öğrenci başarısına etkisi (pilot uygulama). Uludă̆ Üniversitesi Eğitim Fakültesi Dergisi, 24(1), 247-261. 


\section{EK 1. Çalışmada kullanılan hikâye}

\section{GELECEĞİN MUCIZZESI}

İnsanlığın hayatını kökten değiştirecek teknolojik gelişmeler, gün geçtikçe artmaktadır. Bir düşünsenize, herkesin kendi bilgisayarını ürettiği ve emirler verdiği sistemler... Ya da bir deve, dikiş iğnesinin deliğinden geçebilir mi? Resimde de görüldüğü gibi bu artık mümkün. Atomların sonsuz kere tekrar tekrar dönüştürülerek, metrenin milyarda biri kadar boyutlara sahip ürünler; iş göremez haldeki organların yerine yeni organlar, bakteriden daha küçük nanobilgisayarlar ne kadar da ilginç değil mi? Gelişmekte olan bir teknoloji, hayatımızın her alanında kullanıma hazır hale gelmiştir. $\mathrm{Bu}$ teknolojiyle belki de çok daha dayanıklı ulaşım araçları ve paslanmayan, kirlenmeyen eşyalar; hatta kendi kendini temizleyebilen giysiler üretilebilecektir. Peki, tüm bunlar nasıl mümkün olabilir? Maddeyi atomik boyutlarda inceleyip işleyerek çağımızın anahtar

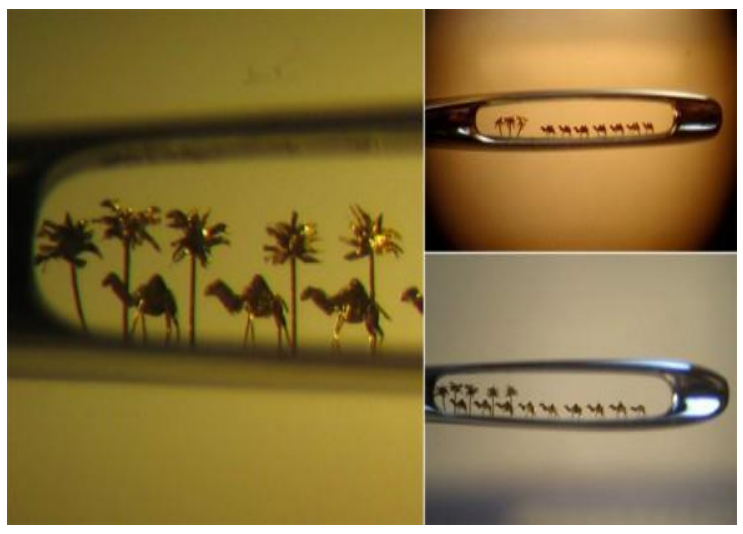
teknolojisi geliştirilmiştir. Bu teknoloji, yaşam kalitesinde ve üretimde artışı amaçlamaktadır.

Öyle bir teknoloji ki; tekstil, boya, kimya, sağlik, elektronik,

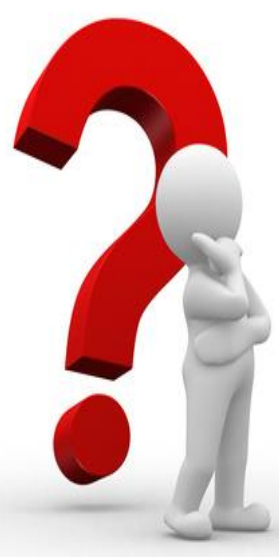
otomotiv, bilgisayar, savunma ve sanayi gibi birçok alanda kullanılmaktadır. Böylece, dünyayı yeniden şekillendirebilecek bilimsel ve teknolojik bir dönem başlamış olacaktır. İnsan beyninin kapasitesini ek nano hafızalarla güçlendirmek, bir milyon sinema filmi alabilen DVD'ler yapmak, uzay araştırmalarında ve havacilıkta yeni roket ve uçak tasarlamak artık hayal olmaktan çıkacaktır. Belki de doğada taklit edilemeyen hiçbir şey kalmayacaktır. Sizce, dünyada bir devrim niteliği taşıyan bu teknoloji günlük hayatımızı nasıl etkiler? Metrenin milyarda biri kadar kullanılan bu küçük şeyler ne olabilir? Küçük ama dünya çapında rağbet görecek kadar büyük bir öneme sahip olan bu teknolojiyle, yeni ürünler nasıl elde edilmektedir? Günlük hayatta işimizi kolaylaştıracak bu teknolojinin faydaları yanında zararları da olabilir mi? Ne dersiniz? 
EK 2. Çalışma Yaprağı

\section{GRUP ADI:}

\section{LOTUS ETKİṠ}

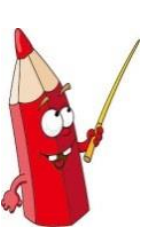

Görür görmez insanı kendine hayran bırakan bir güzellik, Lotus (Nilüfer) Çiçeği, ardında neler gizli! Keşfettikçe hayranlığınız daha da artacak. Zira kendisi bir su bitkisi ve kirli, çamurlu, sulak alanlarda yetişen, oldukça nadide çiçeklerden biri. Sizce, bu eşsiz bitki o kadar çamurun, kirin içinde kendini nasıl şahane bir şekilde korumayı başarabiliyor?

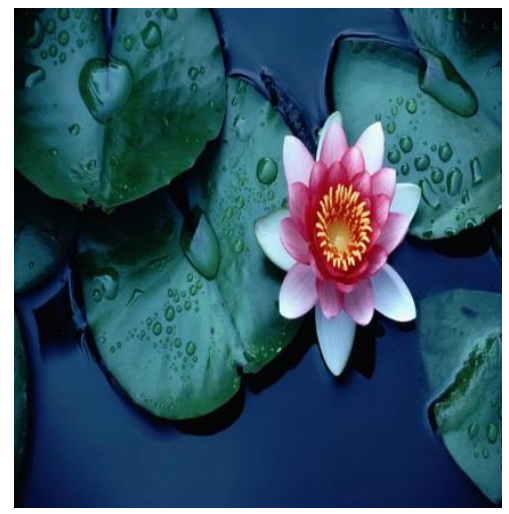

\section{MALZEMELER \\ * Su \\ * Damlalık ya da pipet \\ * Akmaları temizlemek için kâğıt havlu}

* 2 adet lahana yaprağ1

* 2 adet marul yaprağ 1

* Bir miktar toprak

\section{DENEYIN YAPILIŞI}

> Marul yapraklarından birine birkaç damla su damlatın.

> Diğer marul yaprağına toprak dökün ve üzerine su damlatın.

$>$ Lahana yapraklarından birine su damlatın.

> Diğer lahana yaprağına toprak dökün ve üzerine su damlatın.

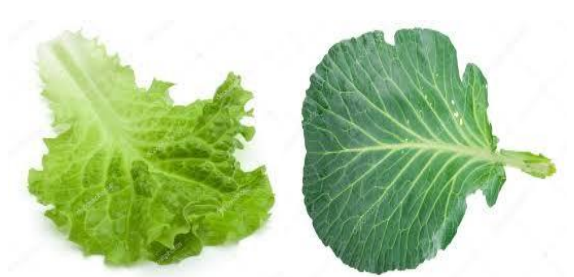

$>$ Gözlemlerinizi tabloya yazın.

\begin{tabular}{|c|c|c|}
\hline \multirow{2}{*}{ Yaprak + Su } & \multicolumn{2}{|c|}{ GÖZLEMLER } \\
\cline { 2 - 3 } & Marul Yaprağı & \\
\hline & & \\
Yaprak+Toprak+Su & & \\
\hline
\end{tabular}

\section{SORULAR}

1. Lahana yaprağı, üzerinde neden su biriktiriyor?

2. Sizce tüm bitkiler Lotus etkisi gösterebilir mi?

3. Lotus bitkisinden ilham alınarak ne tür ürünler geliştirilebilir? 
EK 3. Çalışmada kullanılan başarı testi

\section{AD-SOYAD/RUMUZ: BÖLÜM:}

\section{NANOTEKNOLOJI BAŞARI TESTİ}

1) Nanoteknoloji nedir?

2) Nanoteknoloji hangi amaçlarla kullanılabilir? Açıklayınız.

3) Nanoteknolojinin kullanıldığı bilim dallarına örnekler verebilir misiniz? Açıklayınız.

4) Nanoteknolojinin günlük hayatta kullanıldığını düşünüyor musunuz? Açıklayınız.

5) Nanoteknolojinin yararları hakkındaki düşünceleriniz nelerdir? Açıklayınız.

6) Nanoteknolojinin zararları hakkındaki düşünceleriniz nelerdir? Açıklayınız.

7) Nanoteknolojinin toplum ve çevre üzerinde etkileri hakkında ne düşünüyorsunuz? Açıklayınız. 